Article

\title{
Enhanced Cypermethrin Degradation Kinetics and Metabolic Pathway in Bacillus thuringiensis Strain SG4
}

\author{
Pankaj Bhatt ${ }^{1,2,3}$, Yaohua Huang ${ }^{1,2} \oplus$, Wenping Zhang ${ }^{1,2} \oplus$, Anita Sharma ${ }^{3, *}$ and \\ Shaohua Chen $1,2, *$ (i) \\ 1 State Key Laboratory for Conservation and Utilization of Subtropical Agro-bioresources, \\ Guangdong Province Key Laboratory of Microbial Signals and Disease Control, \\ Integrative Microbiology Research Centre, South China Agricultural University, Guangzhou 510642, China; \\ pankajbhatt.bhatt472@gmail.com (P.B.); 20183138021@stu.scau.edu.cn (Y.H.); \\ 20191047008@stu.scau.edu.cn (W.Z.) \\ 2 Guangdong Laboratory of Lingnan Modern Agriculture, Guangzhou 510642, China \\ 3 Department of Microbiology, College of Basic Sciences and Humanities, G. B Pant University of Agriculture \\ and Technology, Pantnagar 263145, India \\ * Correspondence: shchen@scau.edu.cn (S.C.); bbmas1975@gmail.com (A.S.); Tel.: +86-20-8528-8229 (S.C.); \\ Fax: +86-20-8528-0292 (S.C.)
}

Received: 5 December 2019; Accepted: 3 February 2020; Published: 7 February 2020

\begin{abstract}
Cypermethrin is popularly used as an insecticide in households and agricultural fields, resulting in serious environmental contamination. Rapid and effective techniques that minimize or remove insecticidal residues from the environment are urgently required. However, the currently available cypermethrin-degrading bacterial strains are suboptimal. We aimed to characterize the kinetics and metabolic pathway of highly efficient cypermethrin-degrading Bacillus thuringiensis strain SG4. Strain SG4 effectively degraded cypermethrin under different conditions. The maximum degradation was observed at $32{ }^{\circ} \mathrm{C}, \mathrm{pH} 7.0$, and a shaking speed of $110 \mathrm{rpm}$, and about $80 \%$ of the initial dose of cypermethrin $\left(50 \mathrm{mg} \cdot \mathrm{L}^{-1}\right)$ was degraded in minimal salt medium within 15 days. SG4 cells immobilized with sodium alginate provided a higher degradation rate $(85.0 \%)$ and lower half-life $\left(t_{1 / 2}\right)$ of 5.3 days compared to the 52.9 days of the control. Bioaugmentation of cypermethrin-contaminated soil slurry with strain SG4 significantly enhanced its biodegradation (83.3\%). Analysis of the degradation products led to identification of nine metabolites of cypermethrin, which revealed that cypermethrin could be degraded first by cleavage of its ester bond, followed by degradation of the benzene ring, and subsequent metabolism. A new degradation pathway for cypermethrin was proposed based on analysis of the metabolites. We investigated the active role of $B$. thuringiensis strain SG4 in cypermethrin degradation under various conditions that could be applied in large-scale pollutant treatment.
\end{abstract}

Keywords: Bacillus thuringiensis; bioaugmentation; biodegradation; cypermethrin; kinetics; metabolic pathway

\section{Introduction}

Cypermethrin (( \pm$)$ - $\alpha$-cyano-3-phenoxybenzyl ( \pm )-cis-trans3-(2,2-dichlorovinyl)-2,2-dimethylcyclo propanecarboxylate) is a synthetic pyrethroid that is commonly used against agricultural and household pests. Pyrethroids are applied worldwide to protect crop fields against insects and enhance agricultural production [1,2]. Pyrethroids also play a crucial role in the control of household insects, especially mosquitoes [3]. Low toxicity and adequate crop protection have motivated farmers to frequently apply 
synthetic pyrethroids [4]. Pesticides are important for pest control, but also affect human health and the environment [5-7]. Metabolites of synthetic pyrethroids have been reported in human urine samples, indicating their toxicity to living systems [8]. The microsomal enzyme carboxylesterase metabolizes these chemicals inside the human body [9].

Cypermethrin persistence in the environment varies according to the physiochemical conditions of the soil $[10,11]$. Microbial metabolism determines the fate of cypermethrin in soil and helps to reduce the concentration in the natural environment. Ester bond cleavage is the main route of cypermethrin degradation under laboratory conditions, via hydrolysis to produce alcohol and acid. The alcohol-containing intermediate is further converted into 3-phenobenzoic acid [12,13]. Cypermethrin is a non-polar compound with low water solubility and is therefore adsorbed onto the soil particles, whereas intermediate metabolites are mobile in soil. 3-Phenobenzoic acid is a toxic intermediate of cypermethrin and other pyrethroid degradations, which disrupts endocrine activity [14]. Several cypermethrin-degrading bacterial strains have been reported to effectively use the pesticide as a carbon and nitrogen source [15-18]. Microbial strains of genera Bacillus, Pseudomonas, Acinetobacter, Roultella, Aspergillus, Candida, Trichoderma, and Cunninghamella have been used for the degradation of cypermethrin and other pyrethroids [19-24]. These isolates can degrade up to $80 \%$ of cypermethrin in liquid media [21-24]. Mixed microbial cultures have been reported to degrade cypermethrin more rapidly than axenic culture [25]. However, little is known about the kinetic and metabolic fate of cypermethrin in soil. Soil bacteria exhibit different metabolic pathways for cypermethrin degradation, and this strategy can be effectively applied to remove environmental contaminants [26]. In this study, we investigated the role of Bacillus thuringiensis strain SG4 in cypermethrin biodegradation under conditions similar to the natural environment.

\section{Materials and Methods}

\subsection{Chemicals and Media}

Technical-grade cypermethrin was obtained from the Department of Chemistry, G.B Pant University of Agriculture and Technology, Pantnagar, India. It was dissolved in acetonitrile to prepare a stock solution of $1 \mathrm{mg} \cdot \mathrm{mL}^{-1}$, which was filter sterilized and kept in the refrigerator. Minimal salt medium (MSM; $\left(\mathrm{NH}_{4}\right)_{2} \mathrm{SO}_{4} 2.0 \mathrm{~g} \cdot \mathrm{L}^{-1}, \mathrm{Na}_{2} \mathrm{HPO}_{4} \cdot 12 \mathrm{H}_{2} \mathrm{O} 1.5 \mathrm{~g} \cdot \mathrm{L}^{-1}, \mathrm{KH}_{2} \mathrm{PO}_{4} 1.5 \mathrm{~g} \cdot \mathrm{L}^{-1}, \mathrm{MgSO}_{4} \cdot 7 \mathrm{H}_{2} \mathrm{O} 0.2 \mathrm{~g} \cdot \mathrm{L}^{-1}, \mathrm{CaCl}_{2} \cdot 2 \mathrm{H}_{2} \mathrm{O}$ $0.01 \mathrm{~g} \cdot \mathrm{L}^{-1}, \mathrm{FeSO}_{4} \cdot 7 \mathrm{H}_{2} \mathrm{O} 0.001 \mathrm{~g} \cdot \mathrm{L}^{-1} ; \mathrm{pH} 7.0$ ) and nutrient broth (beef extract 1.0, yeast extract 2.0, peptone 5.0, and sodium chloride $5.0 \mathrm{~g} \cdot \mathrm{L}^{-1} ; \mathrm{pH} 7.0$ ) were used for the cultivation of pesticide-degrading soil bacterial strains. Analytical grade chemicals and solvents were used in this study.

\subsection{Enrichment, Screening, and Identification of Cypermethrin-Degrading Bacteria}

Cypermethrin-contaminated soil samples were collected from the agricultural fields in Pantnagar, Uttarakhand, India. Enrichment was carried out in MSM to isolate bacteria from collected soil samples. We used $1 \mathrm{~g}$ soil for bacterial isolation using the pour plate method. Bacterial colonies were transferred to $50 \mathrm{~mL}$ MSM containing cypermethrin $\left(50 \mathrm{mg} \cdot \mathrm{L}^{-1}\right)$, and residue concentrations at various incubation intervals were quantified using high-performance liquid chromatography (HPLC) (Dionex Corp., Sunnyvale, CA, USA). The SG4 bacterial strain was isolated from the soil samples and selected for further studies based on its cypermethrin-degradation ability. The strain was identified based on a polyphasic approach using its morphological, biochemical, and molecular characteristics $[12,27,28]$.

\subsection{Effect of Temperature, $p H$, and Shaking Speed on the Degradation of Cypermethrin}

To investigate the effects of temperature, $\mathrm{pH}$, and shaking speed on the degradation of cypermethrin by strain SG4, a single-factor test was designed under different temperatures $\left(28,32,36{ }^{\circ} \mathrm{C}\right)$, pH $(5.0,7.0,9.0)$, and shaking speed $(90,110,130 \mathrm{rpm})$ conditions. Strain SG4 was incubated in MSM (pH 7.0) containing $50 \mathrm{mg} \cdot \mathrm{L}^{-1}$ cypermethrin at $32{ }^{\circ} \mathrm{C}$ at $110 \mathrm{rpm}$ on a rotary shaker for 15 days. 
Each treatment was performed in triplicate with non-inoculated samples as the control. Residual pesticide concentration was determined by HPLC [13,29-31].

\subsection{Effect of Immobilization on Cypermethrin Degradation}

\subsubsection{Sodium Alginate Beads}

Cypermethrin biodegradation was tested with immobilized bacterial culture in sodium alginate beads at $32{ }^{\circ} \mathrm{C}$ for 15 days. Sodium alginate beads were prepared by mixing $4 \%$ sodium alginate with homogenized bacterial culture(s). The mixture was poured drop by drop into pre-chilled autoclaved $\mathrm{CaCl}_{2}(0.4 \mathrm{M})$ through a needleless syringe to prepare fine beads $(2 \mathrm{~mm})$ inside the laminar airflow. Beads were stored overnight at $4{ }^{\circ} \mathrm{C}$ [32]. MSM (50 mL) was prepared in replicates in a $100 \mathrm{~mL}$ flask for biodegradation experiment and cypermethrin $\left(50 \mathrm{mg} \cdot \mathrm{L}^{-1}\right)$ was added to the flasks along with 20 sodium alginate beads. We removed $1 \mathrm{~mL}$ aliquots of the broth from each flask on 5 th, 10th, and 15th days and cypermethrin was extracted from the samples. Non-inoculated flasks spiked with cypermethrin served as the control and samples were quantified by HPLC.

\subsubsection{Agar Discs}

Agar discs were also used to analyze the cypermethrin biodegradation with immobilized bacterial isolates at $32{ }^{\circ} \mathrm{C}$ for 15 days. Agar solution $(2.5 \%)$ was sterilized and cooled $\left(44{ }^{\circ} \mathrm{C}\right)$ to prepare agar discs. Homogenized bacterial cultures were mixed with molten agar and poured into Petri dishes aseptically inside a laminar airflow [33,34]. Agar discs of equal size were prepared with a cork borer. We placed $50 \mathrm{~mL}$ MSM in a $100 \mathrm{~mL}$ flask and cypermethrin $\left(50 \mathrm{mg} \cdot \mathrm{L}^{-1}\right)$ was added along with 20 agar discs. We removed a $1 \mathrm{~mL}$ aliquot of the broth from each flask on the 5 th, 10th, and 15th days and cypermethrin was extracted. Non-inoculated flasks spiked with cypermethrin served as the control and all the extracted samples were quantified by HPLC.

\subsection{FTIR Analysis of Cypermethrin Biodegradation}

FTIR analysis was performed to estimate bond stretching during cypermethrin degradation $\left(50 \mathrm{mg} \cdot \mathrm{L}^{-1}\right)$ in MSM $(50 \mathrm{~mL})$ inoculated with an active culture of strain SG4. Non-inoculated flasks with $50 \mathrm{mg} \cdot \mathrm{L}^{-1}$ cypermethrin served as the control, and the experiment was repeated three times. For analysis, a $10 \mathrm{~mL}$ mixture of samples and acetone was prepared, and $10 \mathrm{~mL}$ ethyl acetate was added. After vortexing ( $1 \mathrm{~min})$, the upper layer was collected in new tubes and sodium sulfate $(5 \mathrm{~g})$ was added. Samples were transferred to round-bottomed flasks and evaporated. Cypermethrin was collected in a dried round-bottomed flask with acetonitrile and analyzed using FTIR. Cypermethrin metabolites were extracted with acetonitrile after 15 days of inoculation. Bond stretching was analyzed in the F-IR system at a wavelength of $400-4000 \mathrm{~cm}^{-1}$, at the Department of Biophysics, G. B Pant University of Agriculture and Technology, Pantnagar, India [35,36].

\subsection{Cypermethrin Degradation in Soil Slurry and Metabolite Identification}

The soil slurry method was used to investigate cypermethrin degradation by strain SG4. We placed $50 \mathrm{~g}$ autoclaved soil in $250 \mathrm{~mL}$ flasks, and $20 \mathrm{~mL}$ minimal salt broth was added [37,38]. We then added $1 \mathrm{~mL}$ active bacterial inoculum into each flask containing $100 \mathrm{mg} \cdot \mathrm{L}^{-1}$ cypermethrin and the experiment was performed in triplicate at $32^{\circ} \mathrm{C}$ and $110 \mathrm{rpm}$ on a rotary shaker. Cypermethrin residues were extracted at $0,5,10$, and 15 days of incubation and flasks without the bacterial strain served as the control. Extracted cypermethrin was quantified through HPLC and metabolites were detected via gas chromatography-mass spectrometry (GC-MS; Shimadzu QP-2010 plus with Thermal Desorption System TD 20, New Delhi, India). 


\subsection{Chemical Analysis}

The cypermethrin residues of each experiment were analyzed in triplicate. Cypermethrin was extracted by adding $5 \mathrm{~mL}$ bacterial culture into $20 \mathrm{~mL}$ acetone in a flask. After shaking for $1 \mathrm{~h}$, the mixture was carefully washed with $10 \mathrm{~mL}$ acetone and filtered through a Buchner funnel [39]. The filtrate was collected in a round-bottomed flask and pesticide residue was analyzed with HPLC attached to a $\mathrm{C}_{18}$ reverse-phase column and an ECD-3000RS electrochemical detector. A $10 \mu \mathrm{L}$ mixture of acetonitrile and water $(70: 30, v / v)$ was used as the mobile phase at a flow rate of $1.0 \mathrm{~mL} \cdot \mathrm{min}^{-1}$.

\subsection{Kinetic Analysis of Cypermethrin}

The first-order kinetic equation was followed to fit experimental data of cypermethrin degradation kinetics as follows [40]:

$$
\begin{gathered}
C_{t}=C_{0} e^{-k t} \\
\ln C_{t}=C_{0}-k t
\end{gathered}
$$

where $C_{0}$ is the initial concentration of cypermethrin in the medium, $C_{t}$ is the concentration of cypermethrin at time $t, k$ is the degradation rate constant $\left(\right.$ day $\left.^{-1}\right)$, and $t$ is the reaction time.

The biodegradation half-life $\left(t_{1 / 2}\right)$ of cypermethrin was calculated as

$$
t_{1 / 2}=\ln 2 / k
$$

To calculate $k$, natural logarithm values of $C$ were plotted against time $t$. Percent persistence values at different time intervals were calculated in comparison to cypermethrin recovered on the initial day (0) i.e., $1 \mathrm{~h}$ after the application (100\%). The $k$ of each concentration was computed from the slope of the line [41].

\subsection{Statistical Analysis}

Experiments were arranged as completely randomized designs with three replicates. Data were analyzed by one-way analysis of variance (ANOVA), and means were compared according to Bonferroni's multiple comparisons test using IBM-SPSS software (version 22.0, IBM, New York, NY, USA). Statistical significance was determined by lowest significance differences (LSD) test at $p<0.05$ to examine specific differences between treatments.

\section{Results}

\subsection{Enrichment of Bacterial Strain}

Cypermethrin-degrading bacterial isolate SG4 was enriched and isolated from contaminated agricultural fields and characterized as Gram-positive rod-shaped bacilli. The morphological and biochemical characteristics of strain SG4 are provided in Supplementary Table S1. Strain SG4 efficiently degraded cypermethrin by using it as a source of carbon and nitrogen to grow. Phylogenetic analysis confirmed evolutionary similarities of strain SG4 with previously reported cypermethrin-degrading bacterial strains and was identified as Bacillus thuringiensis strain SG4 (accession number KT186610).

\subsection{Effect of Temperature, $p H$, and Shaking Speed on the Degradation of Cypermethrin by Strain SG4}

The effects of temperature, $\mathrm{pH}$, and shaking speed on the degradation of cypermethrin by strain SG4 were investigated in MSM (Figure 1). Strain SG4 effectively degraded cypermethrin under different conditions. The strain SG4 degraded $72.3 \%, 79.9 \%$, and $76.5 \%$ of cypermethrin at 28,32 , and $36{ }^{\circ} \mathrm{C}$, respectively, with $72.5 \%, 80.8 \%$, and $75.1 \%$ degradation at $\mathrm{pH} 5.0,7.0$, and 9.0, respectively. For the shaking speed, $74.1 \%, 80.5 \%$, and $77.3 \%$ degradation was achieved at 90,110 , and $130 \mathrm{rpm}$, respectively. The maximum degradation was observed at $32{ }^{\circ} \mathrm{C}, \mathrm{pH} 7.0$, and a shaking speed of $110 \mathrm{rpm}$. Under optimal conditions, strain SG4 degraded cypermethrin rapidly without a lag phase, with a $k$ value of 
0.1035 day $^{-1}$ and a $t_{1 / 2}$ of 6.7 days. In the non-inoculated control, the $k$ and $t_{1 / 2}$ values were 0.990 day $^{-1}$ and 165.0 days, respectively (Table 1 ). The $t_{1 / 2}$ value for cypermethrin significantly decreased when inoculated with strain SG4 in MSM.

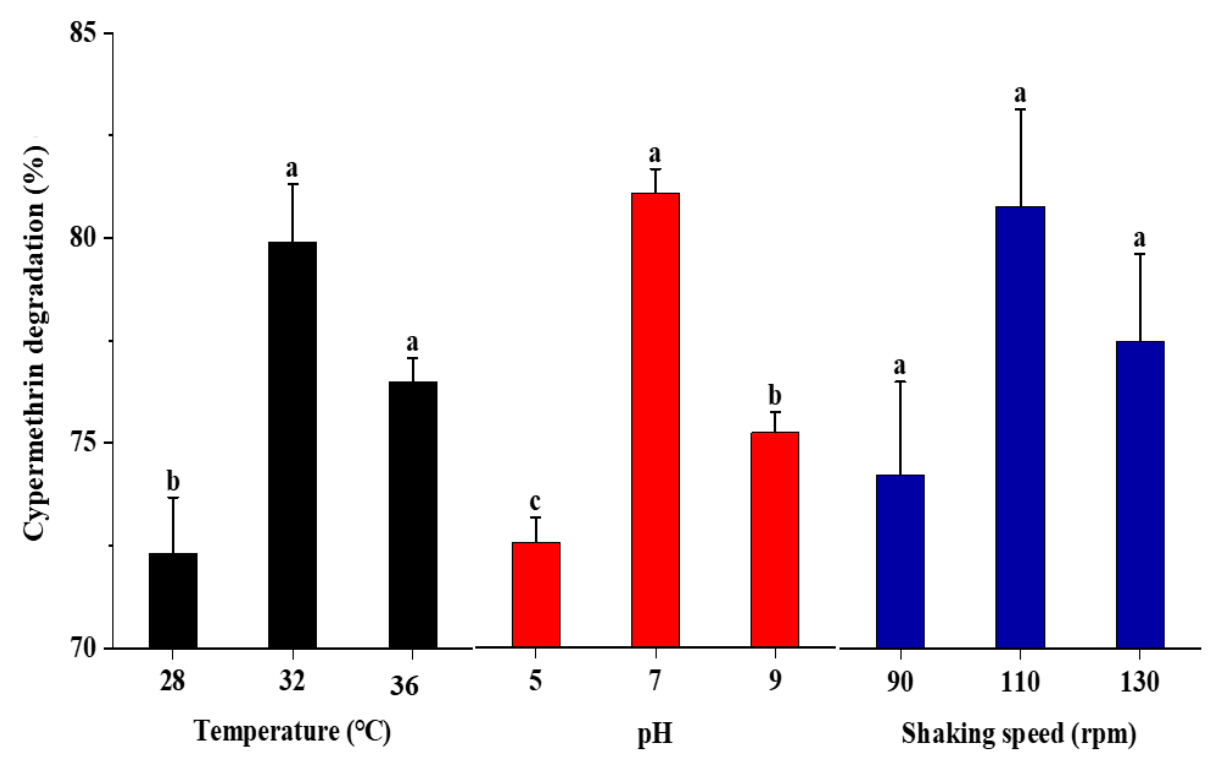

Figure 1. Effect of temperature, $\mathrm{pH}$, and shaking speed on the degradation of cypermethrin by strain SG4. The data presented are mean \pm standard errors of three independent experiments. Statistical analysis was performed by one way ANOVA of Duncan method, and different letters indicate significant differences $(p<0.05)$ between treatments.

Table 1. Degradation kinetics of cypermethrin with strain SG4 in MSM and soil slurry.

\begin{tabular}{ccccc}
\hline Treatment & Regression Equation & $\boldsymbol{k}$ (day $\left.^{-\mathbf{1}}\right)$ & $\boldsymbol{R}^{\mathbf{2}}$ & $\boldsymbol{t}_{\mathbf{1 / 2}}$ (days) \\
\hline MSM & $\ln \left(\mathrm{C}_{\mathrm{t}} / \mathrm{C}_{0}\right)=-0.0042 \mathrm{x}+4.6074$ & 0.0042 & 0.990 & 165.0 \\
MSM + SG4 & $\ln \left(\mathrm{C}_{\mathrm{t}} / \mathrm{C}_{0}\right)=-0.1035 \mathrm{x}+4.725$ & 0.1035 & 0.954 & 6.7 \\
Soil slurry & $\ln \left(\mathrm{C}_{\mathrm{t}} / \mathrm{C}_{0}\right)=-0.0039 \mathrm{x}+4.599$ & 0.0039 & 0.999 & 177.7 \\
Soil slurry + SG4 & $\ln \left(\mathrm{C}_{\mathrm{t}} / \mathrm{C}_{0}\right)=-0.1134 \mathrm{x}+4.702$ & 0.113 & 0.968 & 0.70 \\
\hline
\end{tabular}

Initial cypermethrin concentration was $50 \mathrm{mg} \cdot \mathrm{L}^{-1}$ in $\mathrm{MSM}$ and $100 \mathrm{mg} \cdot \mathrm{kg}^{-1}$ in soil. The linear equation was derived from chemical data of $C_{0}$ and $C_{\mathrm{t}}$ to calculate degradation rate constant $(k)$, determination coefficient $\left(R^{2}\right)$ and half-life $\left(t_{1 / 2}\right)$ values. $t_{1 / 2}$ : cypermethrin disappearance time in days; $C_{0}$ and $C_{t}$ : cypermethrin concentration at the initial and final stage of the experiment, respectively; MSM: minimal salt medium.

\subsection{Cypermethrin Degradation with Immobilized Culture}

The bioremediation capability of immobilized B. thuringiensis strain SG4 was determined in MSM with immobilized bacterial cells, using sodium alginate and agar disc as the matrix materials. Cypermethrin biodegradation by immobilized bacterial cultures in sodium alginate beads was found to be $28.0 \%$ and $73.0 \%$ on Days 5 and 10, respectively whereas maximum degradation of $85.3 \%$ was observed on Day 15 (Figure 2). The degradation with immobilized agar disc was $31.0 \%, 60.0 \%$, and $81.0 \%$ on Days 5, 10, and 15, respectively. Cypermethrin degradation kinetics with immobilized strain SG4 demonstrated the better efficiency of these treatments (Table 2). Cypermethrin degradation with an external nitrogen source followed the first-order reaction model. Cypermethrin $t_{1 / 2}$ in control with sodium alginate and strain SG4 treatments was 52.9 and 5.3 days, respectively. Agar-disc-based immobilized treatment resulted in cypermethrin $t_{1 / 2}$ values of 50.9 and 6.4 days in control and strain SG4 treatment, respectively; the $k$ values for sodium alginate control and strain SG4 were 0.0131 and 0.1330 day $^{-1}$, respectively; whereas for the agar disc control and strain SG4 the $k$ values were noted as 0.0136 and 0.1039 day $^{-1}$, respectively. We confirmed that the degradation kinetics of sodium-alginate-based immobilized strain SG4 was more effective than the agar discs. 


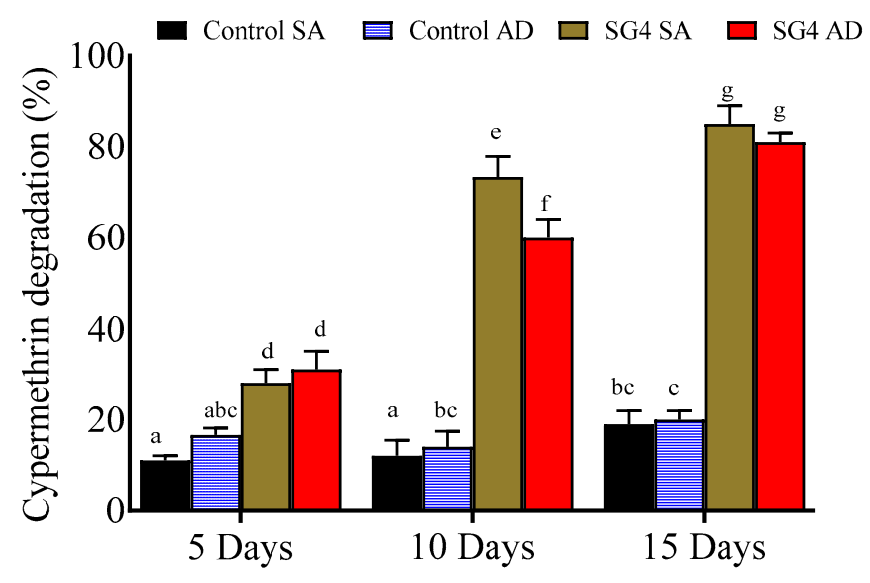

Figure 2. Effect of strain SG4 immobilization (sodium alginate and agar disc) on the degradation of cypermethrin. The data presented are mean \pm standard errors of three independent experiments. Statistical analysis was performed by one way ANOVA of Duncan method, and different letters indicate significant differences $(p<0.05)$ between treatments. SA: sodium alginate, AD: agar discs.

Table 2. Degradation kinetics of cypermethrin with immobilized culture.

\begin{tabular}{ccccc}
\hline Treatment & Regression Equation & $\boldsymbol{k}$ (day $^{-\mathbf{1}}$ & $\boldsymbol{R}^{\mathbf{2}}$ & $\boldsymbol{t}_{\mathbf{1 / 2}}$ (days) \\
\hline MSM + SA & $\ln \left(\mathrm{C}_{\mathrm{t}} / \mathrm{C}_{\mathrm{o}}\right)=-0.0131 x+4.5868$ & 0.0131 & 0.933 & 52.9 \\
$\mathrm{MSM}+\mathrm{SA}+\mathrm{SG} 4$ & $\ln \left(\mathrm{C}_{\mathrm{t}} / \mathrm{C}_{\mathrm{o}}\right)=-0.1336 \mathrm{x}+4.7126$ & 0.133 & 0.966 & 5.3 \\
$\mathrm{MSM}+\mathrm{AD}$ & $\ln \left(\mathrm{C}_{\mathrm{t}} / \mathrm{C}_{\mathrm{o}}\right)=-0.0136 \mathrm{x}+4.5732$ & 0.0136 & 0.859 & 50.9 \\
$\mathrm{MSM}+\mathrm{AD}+\mathrm{SG} 4$ & $\ln \left(\mathrm{C}_{\mathrm{t}} / \mathrm{C}_{\mathrm{o}}\right)=-0.1089 \mathrm{x}+4.6867$ & 0.1089 & 0.977 & 6.4 \\
\hline
\end{tabular}

Initial cypermethrin concentration was $50 \mathrm{mg} \cdot \mathrm{L}^{-1}$. A linear equation was derived from chemical data of $C_{0}$ and $C_{\mathrm{t}}$, to calculate $k, R^{2}$, and $t_{1 / 2}$ values. SA: sodium alginate; AD: agar discs.

\subsection{Degradation Kinetics of Cypermethrin in Soil Slurry}

Cypermethrin degradation in soil slurry inoculated with B. thuringiensis strain SG4 followed first-order reaction kinetics. Inoculation of soil slurry resulted in $25.7 \%$ and $63.7 \%$ cypermethrin degradation on Days 5 and 10, respectively, which increased to 83.3\% on Day 15 (Figure 3). The degradation kinetics of cypermethrin in soil slurry were reflected in the $t_{1 / 2}$ value 177.7 and 0.7 days in control and strain-SG4-treated samples, respectively. The $k$ values in soil slurry were 0.0039 and 0.113 day $^{-1}$ in control and strain SG4 treatment, and the $R^{2}$ values were 0.999 and 0.968 , respectively (Table 1). The observation of soil slurry suggested that B. thuringiensis strain SG4 has a strong cypermethrin degradation ability in agricultural fields.

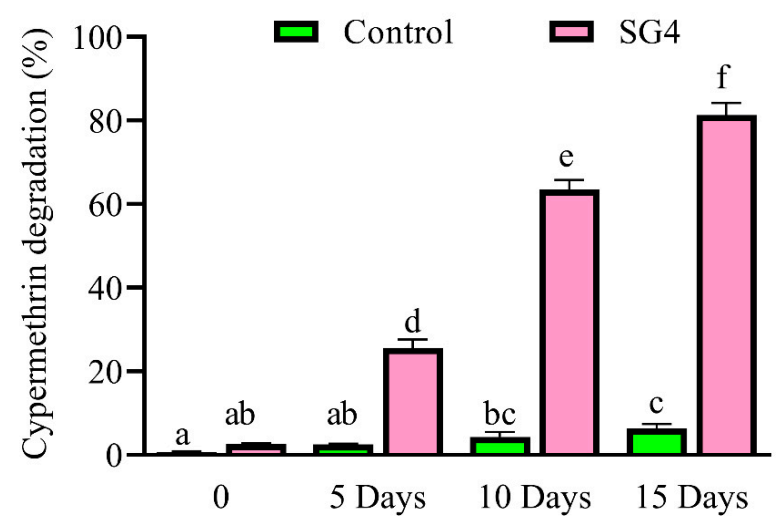

Figure 3. Cypermethrin degradation in soil slurry with strain SG4. The data presented are mean \pm standard errors of three independent experiments. Statistical analysis was performed by one way ANOVA of Duncan method, and different letters indicate significant differences $(p<0.05)$ between treatments. 


\subsection{FTIR Analysis of Cypermethrin Metabolites}

FTIR studies were performed to characterize bonding or stretching vibrations in cypermethrin under bacterial treatments. Different peaks in the control represented a variety of chemical bonds in the cypermethrin structure. Four peaks were observed in the control at 1000 to $2000 \mathrm{~cm}^{-1}$ and $3000 \mathrm{~cm}^{-1}$, which corresponded to stretching in the $\mathrm{C}-\mathrm{C}, \mathrm{C}-\mathrm{C}, \mathrm{C}-\mathrm{N},(\mathrm{C}=\mathrm{O})-\mathrm{O}-$, and $\mathrm{C}-\mathrm{H}$ bonds of cypermethrin. Conversely, peaks were absent in the strain-SG4-treated sample, revealing effective cypermethrin degradation (Figure 4). The results confirmed that cypermethrin degradation with strain SG4 is a systematic process that includes the opening and conversion of aromatic rings to give another intermediate compound.
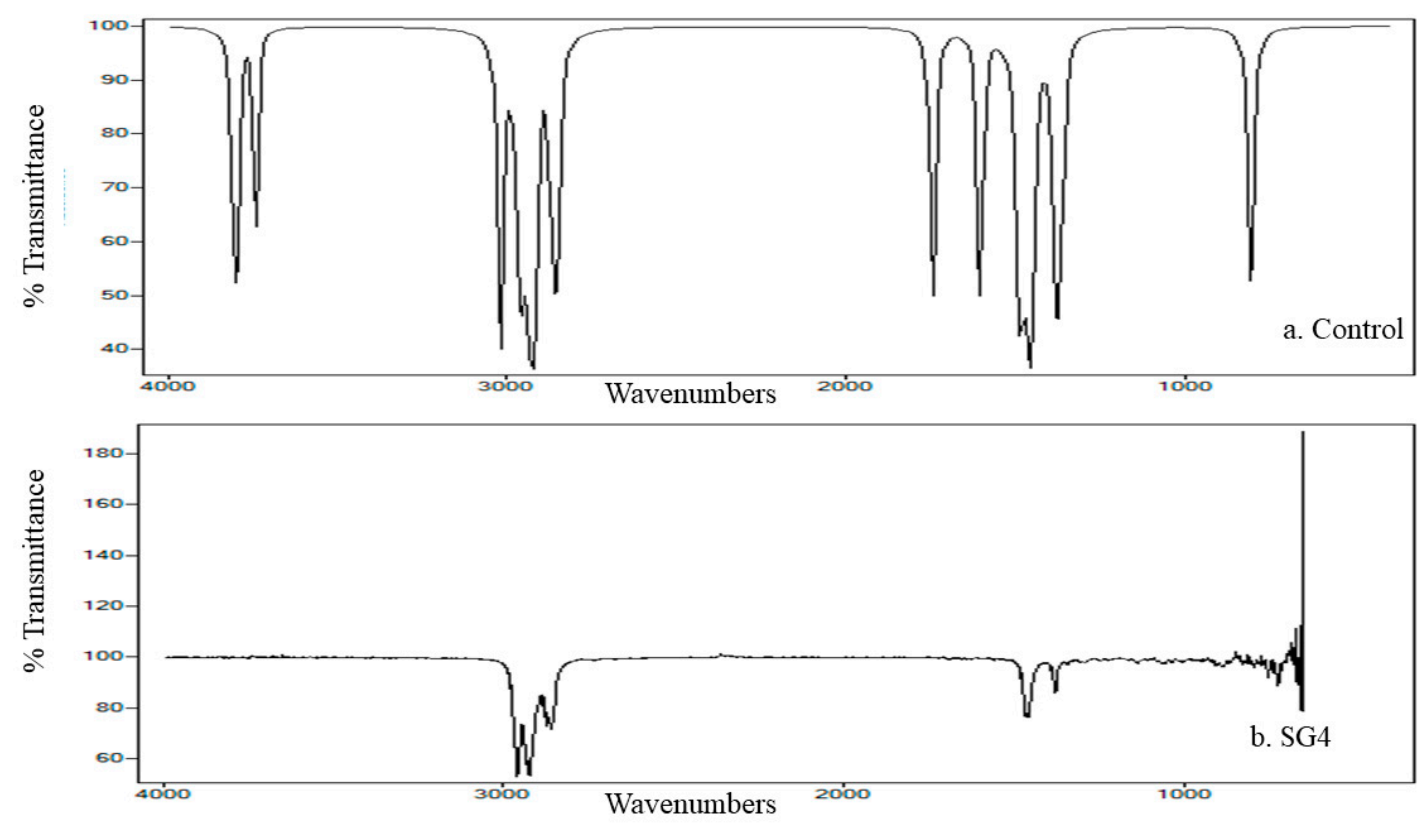

Figure 4. FTIR analysis of cypermethrin degradation with strain SG4 in minimal salt medium.

\subsection{Identification of Metabolites}

To identify cypermethrin degradation mechanism with B. thuringiensis strain SG4, HPLC and GC-MS were applied for metabolite characterization. HPLC-based quantification confirmed the degradation of cypermethrin on different days. The GC-MS chromatogram of cypermethrin with strain SG4 is shown in Supplementary Figure S1. Metabolites were characterized by comparison with the GC-MS compound library (Table 3). Bacterial strain SG4 degraded cypermethrin into smaller compounds with lower molecular weight. In soil slurry samples, the metabolite detected at retention time 4.123 min was identified as phenol, whereas the marker metabolite 3-phenoxybenzaldehyde was detected at a retention time of 13.728 with $\mathrm{m} / \mathrm{z}$ 198. Table 3 describes the $\mathrm{m} / \mathrm{z}$ values of the metabolites of strain SG4 in soil. The metabolic pathway was constructed based on the identified cypermethrin degradation metabolites (Figure 5). The metabolic pathway suggested that cypermethrin was initially degraded by the cleavage of the ester bond, followed by the cleavage of a benzene ring and subsequent metabolism. Analysis of metabolic products confirmed that no toxic intermediate was produced during strain-SG4-based degradation. Therefore, this strain can effectively and completely degrade cypermethrin via its metabolic pathway. 
Table 3. Gas chromatography-mass spectrometry (GC-MS) analysis of the cypermethrin degradation metabolites.

\begin{tabular}{|c|c|c|c|c|}
\hline $\begin{array}{l}\text { Cypermethrin } \\
\text { Degradation } \\
\text { Metabolites } \\
\text { Sequence }\end{array}$ & $\begin{array}{l}\text { Retention } \\
\text { Time (min) }\end{array}$ & Identified Metabolites & $\begin{array}{l}\text { Molecular } \\
\text { Weight (MW) }\end{array}$ & Chemical Structure \\
\hline $\mathrm{CP} 1$ & 4.123 & Phenol & 94 & \\
\hline $\mathrm{CP} 2$ & 11.050 & Benzoic acid, 2,5-dimethyl & 150.17 & $\mathrm{COOH}$ \\
\hline $\mathrm{CP} 3$ & 13.724 & $\begin{array}{l}\text { 2-Hydroxy-3- phenoxy- } \\
\text { benzeneacetonitrile }\end{array}$ & 225 & \\
\hline $\mathrm{CP} 4$ & 13.728 & 3-Phenoxybenzaldehyde & 198 & \\
\hline CP5 & 14.289 & Phthalic acid & 166.14 & \\
\hline CP6 & 15.942 & 2-Pentadecanone & 226.4 & \\
\hline $\mathrm{CP7}$ & 20.00 & 3-Phenoxybenzoate & 228 & \\
\hline $\mathrm{CP} 8$ & 23.960 & Cypermethrin & 415 & \\
\hline $\mathrm{CP9}$ & 24.098 & $\begin{array}{l}\text { 3-(2,2-Dichloroethenyl)-2,2-dimethyl } \\
\text { cyclopropanecarboxylate }\end{array}$ & 236 & \\
\hline
\end{tabular}




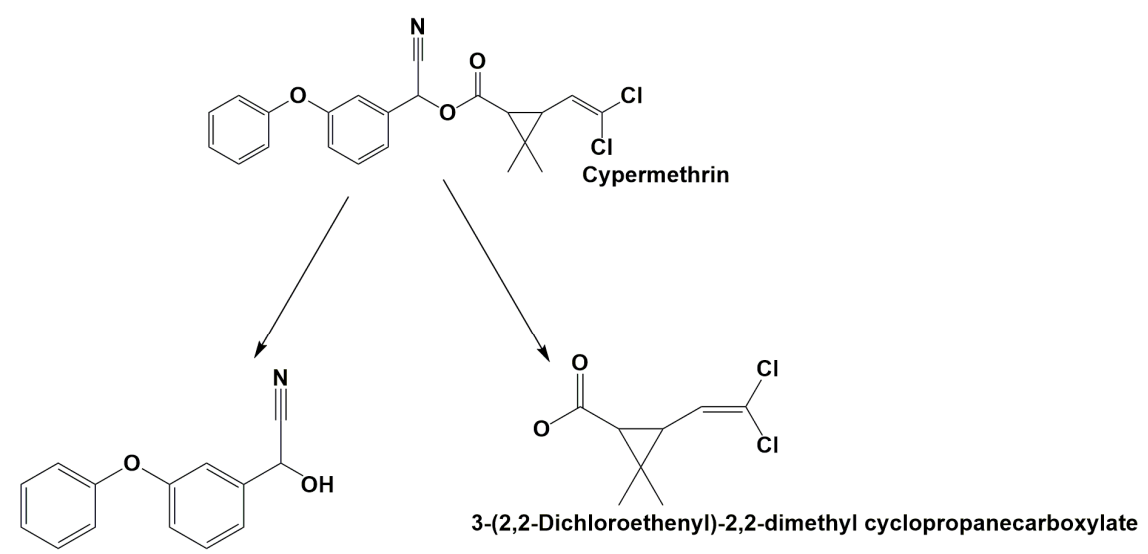

2- Hydroxy-3- phenoxy- benzene acetonitrile

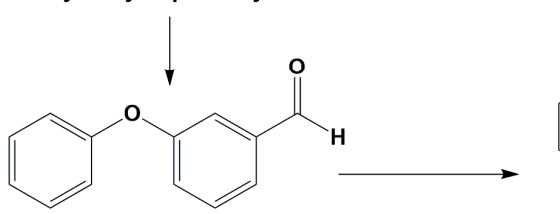

3-Phenoxybenzaldehyde

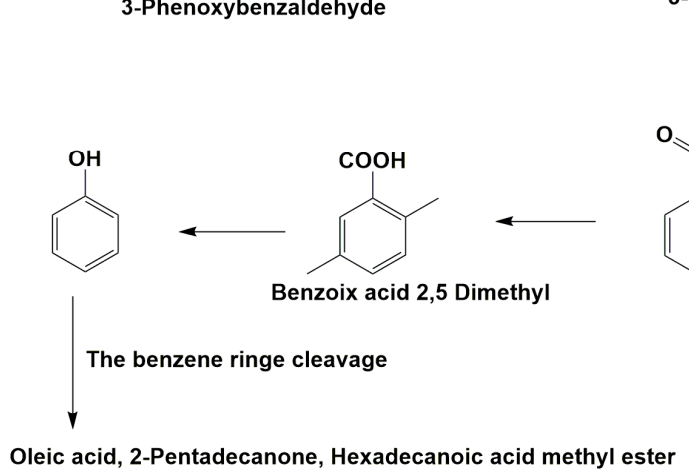<smiles>O=C(O)c1cccc(Oc2ccccc2)c1</smiles>

3-Phenoxybenzoic acid<smiles>O=C(O)c1ccccc1C(=O)O</smiles>

Phthalic acid

Figure 5. Metabolic pathway of cypermethrin degradation of strain SG4.

\section{Discussion}

Since the late 1980s, extensive cypermethrin applications in the agriculture and household sectors have led to toxic effects on organisms, necessitating its removal from contaminated environments. In this study, a cypermethrin-degrading bacterium was isolated from a pyrethroid-contaminated agricultural field. The bacterial isolate was characterized as B. thuringiensis strain SG4 (accession no. KT186610). Strain SG4 efficiently degraded cypermethrin in soil slurry and immobilized the culture with sodium alginate/agar discs. B. thuringiensis (Bt) is a bacterium well-known for its broad capabilities and it is widely used in biological control [42]. Bt has been reported for the degradation of cypermethrin and other pyrethroids $[17,42,43]$. However, the potential use of $\mathrm{Bt}$ in the bioremediation of pyrethroid-contaminated environments has not received adequate attention. Proteomics study of strain SG4 has confirmed differential protein expressions in the presence of cypermethrin [17]. Other cypermethrin-degrading microbial genera mainly include Pseudomonas, Micrococcus, Acinetobacter, Aspergillus, Trichoderma, and Candida [1,2,44-46]. These microbes use pyrethroids as the sole sources of carbon and nitrogen to fulfill their nutritional requirements [1]. Therefore, removal using a microbial system is more common compared with other modes of remediation. The key enzyme degrading cypermethrin and other pyrethroids belongs to the hydrolase family of enzymes known as esterases [47]. All the indigenous microbial strains with the potential for pyrethroid degradation are positive for esterase activity [48].

Temperature, $\mathrm{pH}$, and shaking speed are considered important factors that influence the xenobiotic degradation ability of microbes $[13,28,30]$. Under the optimal conditions $\left(32{ }^{\circ} \mathrm{C}, \mathrm{pH} 7.0\right.$, and $\left.110 \mathrm{rpm}\right)$, 
strain SG4 degraded cypermethrin with a maximum degradation rate ( $k$ value of 0.1035 day $\left.^{-1}\right)$. Therefore, these conditions were used for all the experiments. These results were consistent with findings reported by Chen et al. [13] who found that $\beta$-cypermethrin biodegradation likely occurs at neutral and alkaline conditions. Our results also showed that the maximum degradation of cypermethrin was achieved at pH 7.0. Strain SG4 effectively degraded cypermethrin at various conditions $\left(28-36{ }^{\circ} \mathrm{C}\right.$ and $\left.\mathrm{pH} 5.0-9.0\right)$. This is a very important feature of an organism to be used for bioremediation in variable environments.

Cypermethrin and its intermediate metabolites were effectively detected and characterized by FTIR analysis [49]. The main cypermethrin peaks were found in the control, whereas these peaks were absent in strain-SG4-treated samples. The appearance of new peaks after bacterial degradation of cypermethrin showed that it was degraded by the cleavage of ester bond stretching. Microbial treatment of cypermethrin results in stretching of $\mathrm{C}=\mathrm{C}$ chloroalkenes, benzene ring vibration, deformation in $\mathrm{R}-\mathrm{CH}_{2}-\mathrm{CN}$, and $(\mathrm{C}=\mathrm{O})-\mathrm{O}$ bond [49]. Ether cyanate and ester bond stretching were also observed with Bacillus sp. SG2 after 15 days of cypermethrin degradation. Biodegraded cypermethrin with Bacillus sp. SG2 revealed major changes in the range of 100 to $1650 \mathrm{~cm}^{-1}$ and 2259 to $3431 \mathrm{~cm}^{-1}$ [12]. Photolytic degradation with similar peaks, also confirmed by FTIR, suggested that the basic mode of bond cleavage is the same for all processes [50]. Similarly, previous studies reported that cypermethrin is degraded through ester bond cleavage, releasing different intermediate compounds [15,21]. The FTIR analysis of pesticide residues can be confirmed on the basis of bond stretching with the corresponding peak area. The position of the bond cleavage site in pesticides can be confirmed using FTIR [51].

The study of an organism's metabolic pathways is crucial for analyzing the biodegradation potential of a microorganism. Intermediate metabolites are sometimes more toxic than the parent compound [52-54]. We confirmed that strain SG4 produced non-toxic intermediates while effectively degrading cypermethrin. Our results aligned with previous reports on other bacterial strains $[28,30,43]$. Hydrolysis of cypermethrin was mediated via the cleavage of the ester bond, resulting in the formation of acid and alcohol [1]. The proposed degradation pathway of cypermethrin with strain SG4 is shown in Figure 5. The results revealed that cypermethrin was initially degraded into two metabolites: 3-(2,2-dichloroethenyl)-2,2-dimethyl cyclopropanecarboxylate and 2-hydroxy-2(3-phenoxyphenyl) acetonitrile. 2-Hydroxy-2(3-phenoxyphenyl) acetonitrile was then converted into 3-phenoxybenzaldehyde, which is considered a marker metabolic intermediate of cypermethrin and pyrethroid degradation. Previous studies have reported that this step is catalyzed by oxynitrilase $[55,56]$. The intermediate compound 3-phenoxybenzaldehyde appeared in small quantities during the initial phase of the experiment, but disappeared completely due to the effect of strain SG4. 3-Phenoxybenzaldehyde can be easily transformed via a bacterial system, as similarly reported by Birolli et al. [57]. 3-Phenoxybenzaldehyde can be converted into 3-phenoxybenzoic acid using the enzyme aldehyde dehydrogenase [58]. 3-Phenoxybenzoic acid can be converted into phthalic acid, which can further be converted into benzoic acid 2,5-dimethyl using the transferase family enzyme. This benzoic acid 2,5-dimethyl is further converted to phenol. These findings were similar to those previously reported in the literature [15]. The bacterium successfully grows by using and converting this toxic insecticide into non-toxic metabolic compounds. Similar results have been observed with different strains of bacteria and fungi [59]. Several degradation mechanisms for cypermethrin and other pyrethroids have been identified in bacterial strains of Stenotrophomonas, Acinetobacter, Bacillus, Raoultella, Pseudomonas, and Brevibacterium, and fungal strains Aspergillus, Candidia, and Trichoderma $[2,15,19,20,59-61]$. We propose the possible metabolic degradation pathway of cypermethrin with strain SG4 but, in natural conditions, the degradation could proceed via both biotic and abiotic reactions occurring in environmental conditions.

The addition of sodium alginate and agar discs with B. thuringiensis strain SG4 enhanced cypermethrin degradation compared with freely suspended cells. Tallur et al. suggested that agar disc and sodium alginate stabilize membrane permeability and offer protection against toxic intermediates [44]. During the study, we found the degradation of cypermethrin with sodium 
alginate $(85.3 \%)$ to be higher compared to that with agar discs $(81.0 \%)$. Increased surface area and stability associated with sodium alginate might have been the reason for this result. Immobilized microbial cells come into contact with microbes more frequently compared to freely suspended cells. An esterase-enzyme-based assay for pyrethroids suggested that the immobilization technique more completely degrades cypermethrin from the environment [32,62,63]. We also isolated efficient cypermethrin-degrading bacterial strain SG4 from contaminated agricultural fields, which then successfully degraded cypermethrin in soil slurry. Usually, isolated degrading microbes fail to degrade xenobiotics when used for the bioremediation of contaminated soil $[28,64,65]$. In this study, bioaugmentation of cypermethrin-contaminated soil with strain SG4 substantially enhanced its degradation and $83.3 \%$ of cypermethrin was removed from soil within 15 days. Kinetics analysis revealed that its $t_{1 / 2}$ was reduced by 177 days in soil compared with soil without the SG4 strain. Unlike most bacterial isolates, strain SG4 has an exceptional ability to degrade pollutants in soil, highlighting its potential as a potent strain for the bioremediation of pyrethroid-contaminated environments.

\section{Conclusions}

B. thuringiensis SG4 uses cypermethrin as a carbon and nitrogen source, enabling its colonization of a niche area in a natural ecosystem where cypermethrin is present under limited nutrient conditions. Strain SG4 degraded cypermethrin in minimal medium, soil slurry, and in an immobilized culture assay with sodium alginate and agar disc beads. Our findings suggest that strain SG4 can efficiently degrade cypermethrin and similar ester-bond-containing pesticides. Our study of metabolites revealed that strain SG4 follows a complete degradation pathway to degrade cypermethrin. The degradation kinetics of cypermethrin under various treatments indicated that the strain could be used in large-scale applications in contaminated soil and water areas. Analysis with high-throughput techniques suggested that strain SG4 should be further explored to increase the understanding of the molecular machinery that regulates its degradation ability of toxic insecticides.

Supplementary Materials: The following are available online at http://www.mdpi.com/2076-2607/8/2/223/s1.

Author Contributions: Conceptualization: P.B., A.S., and S.C.; methodology: P.B.; data analysis: P.B., Y.H., W.Z., and S.C.; writing—original draft preparation: P.B.; writing—review and editing: P.B., Y.H., W.Z., A.S., and S.C.; supervision, funding acquisition, and project administration: A.S. and S.C. All authors have read and agreed to the published version of the manuscript.

Funding: This research was partly funded by Key-Area Research and Development Program of Guangdong Province (2018B020206001), National Natural Science Foundation of China (31401763) and Guangdong Special Branch Plan for Young Talent with Scientific and Technological Innovation (2017TQ04N026).

Acknowledgments: Authors are thankful to the South China Agricultural University, Guangzhou, China, for providing necessary facilities to prepare the manuscript. The research station provided by the G.B Pant University of Agriculture and Technology, Pantnagar, U.S Nagar, India, is highly acknowledged.

Conflicts of Interest: The authors declare no conflict of interest. The funders had no role in the design of the study; in the collection, analyses, or interpretation of data; in the writing of the manuscript, or in the decision to publish the results.

\section{References}

1. Bhatt, P.; Huang, Y.; Zhan, H.; Chen, S. Insight into microbial applications for the biodegradation of pyrethroid insecticides. Front. Microbiol. 2019, 10, 1778. [CrossRef] [PubMed]

2. Cycon, M.; Piotrowska-Seget, Z. Pyrethroid-degrading microorganisms and their potential for the bioremediation of contaminated soils: A review. Front. Microbiol. 2016, 7, 1463. [CrossRef] [PubMed]

3. Akbar, S.; Sultan, S.; Kertesz, M. Bacterial community analysis of cypermethrin enrichment cultures and bioremediation of cypermethrin contaminated soils. J. Basic Microbiol. 2015, 55, 819-829. [CrossRef]

4. Yao, G.; Gao, J.; Zhang, C.; Jiang, W.; Wang, P.; Liu, X.; Liu, D.; Zhou, Z. Enantioselective degradation of the chiral alpha-cypermethrin and detection of its metabolites in five plants. Environ. Sci. Pollut. Res. 2018, 26, 1558-1564. [CrossRef] 
5. Tang, W.; Wang, D.; Wang, J.; Wu, Z.; Li, L.; Huang, M.; Xu, S.; Yan, D. Pyrethroid pesticide residues in the global environment: An overview. Chemosphere 2018, 191, 990-1007. [CrossRef] [PubMed]

6. Huang, Y.; Zhan, H.; Bhatt, P.; Chen, S. Paraquat degradation from contaminated environments: Current achievements and perspectives. Front. Microbiol. 2019, 10, 1754. [CrossRef]

7. Zhan, H.; Feng, Y.; Fan, X.; Chen, S. Recent advances in glyphosate biodegradation. Appl. Microbiol. Biotechnol. 2018, 10, 5033-5043. [CrossRef]

8. Bragança, I.; Mucha, A.P.; Tomasino, M.P.; Santos, F.; Lemos, P.C.; Delerue-Matos, C.; Domingues, V.F. Deltamethrin impact in a cabbage planted soil: Degradation and effect on microbial community structure. Chemosphere 2019, 12, 1179-1186. [CrossRef]

9. Wang, D.; Zou, L.; Jin, Q.; Hou, J.; Ge, G.; Yang, L. Human carboxylesterases: A comprehensive review. Acta Pharm. Sin. B 2018, 8, 699-712. [CrossRef]

10. Chen, S.; Lin, Q.; Xiao, Y.; Deng, Y.; Chang, C.; Zhong, G.; Hu, M.; Zhang, L.H. Monooxygenase, a novel beta-cypermethrin degrading enzyme from Streptomyces sp. PLoS ONE 2013, 8, e75450. [CrossRef]

11. Chen, S.; Geng, P.; Xiao, Y.; Hu, M. Bioremediation of $\beta$-cypermethrin and 3-phenoxybenzaldehyde contaminated soils using Streptomyces aureus HP-S-01. Appl. Microbiol. Biotechnol. 2012, 94, 505-515. [CrossRef]

12. Pankaj; Sharma, A.; Gangola, S.; Khati, P.; Kumar, G.; Srivastava, A. Novel pathway of cypermethrin biodegradation in a Bacillus sp. strain SG2 isolated from cypermethrin-contaminated agriculture field. 3 Biotech 2016, 6, 45.

13. Chen, S.; Hu, M.; Liu, J.; Zhong, G.; Yang, L.; Rizwan-ul-Haq, M.; Han, H. Biodegradation of beta-cypermethrin and 3-phenoxybenzoic acid by a novel Ochrobactrum lupini DG-S-01. J. Hazard. Mater. 2011, 187, 433-440. [CrossRef]

14. Chen, S.; Hu, Q.; Hu, M.; Luo, J.; Weng, Q.; Lai, K. Isolation and characterization of a fungus able to degrade pyrethroids and 3-phenoxybenzaldehyde. Bioresour. Technol. 2011, 102, 8110-8116. [CrossRef]

15. Tallur, P.N.; Megadi, V.B.; Ninnekar, H.Z. Biodegradation of cypermethrin by Micrococcus sp. strain CPN 1. Biodegradation 2008, 19, 77-82. [CrossRef]

16. Chen, S.; Chang, C.; Deng, Y.; An, S.; Dong, Y.H.; Zhou, J.; Hu, M.; Zhong, G.; Zhang, L.H. Fenpropathrin biodegradation pathway in Bacillus sp. DG-02 and its potential for bioremediation of pyrethroid-contaminated soils. J. Agric. Food Chem. 2014, 62, 2147-2157. [CrossRef]

17. Pankaj; Negi, G.; Gangola, S.; Khati, P.; Kumar, G.; Srivastava, A.; Sharma, A. Differential expression and characterization of cypermethrin-degrading potential proteins in Bacillus thuringiensis strain, SG4. 3 Biotech 2016, 6, 255.

18. Xiao, Y.; Chen, S.; Gao, Y.; Hu, W.; Hu, M.; Zhong, G. Isolation of a novel beta-cypermethrin degrading strain Bacillus subtilis BSF01 and its biodegradation pathway. Appl. Microbiol. Biotechnol. 2015, 99, 2849-2859. [CrossRef]

19. Birolli, W.G.; Vacondio, B.; Alvarenga, N.; Seleghim, M.H.R.; Porto, A.L.M. Enantioselective biodegradation of the pyrethroid ( \pm )-lambda-cyhalothrin by marine-derived fungi. Chemosphere 2018, 197, 651-660. [CrossRef]

20. Cycoń, M.; Żmijowska, A.; Piotrowska-Seget, Z. Enhancement of deltamethrin degradation by soil bioaugmentation with two different strains of Serratia marcescens. Int. J. Environ. Sci. Technol. 2014, 11, 1305-1316. [CrossRef]

21. Lin, Q.; Chen, S.; Hu, M.; Rizwan-ul-Haq, M.; Yang, L.; Li, H. Biodegradation of cypermethrin by a newly isolated actinomycetes HU-S-01 from wastewater sludge. Int. J. Environ. Sci. Technol. 2011, 8, 45-56. [CrossRef]

22. Chen, S.; Yang, L.; Hu, M.; Liu, J. Biodegradation of fenvalerate and 3-phenoxybenzoic acid by a novel Stenotrophomonas sp. strain ZS-S-01 and its use in bioremediation of contaminated soils. Appl. Microbiol. Biotechnol. 2011, 90, 755-767. [CrossRef]

23. Guo, P.; Wang, B.; Hang, B.J.; Li, L.; Ali, S.W.; He, J.; Li, S. Pyrethroid-degrading Sphingobium sp. JZ-2 and the purification and characterization of a novel pyrethroid hydrolase. Int. Biodeterior. Biodegrad. 2009, 63, 1107-1112. [CrossRef]

24. Zhang, C.; Wang, S.; Yan, Y. Isomerization and biodegradation of beta-cypermethrin by Pseudomonas aeruginosa CH7 with biosurfactant production. Bioresour. Technol. 2011, 102, 7139-7146. [CrossRef]

25. Chen, S.; Luo, J.; Hu, M.; Lai, K.; Geng, P.; Huang, H. Enhancement of cypermethrin degradation by a coculture of Bacillus cereus ZH-3 and Streptomyces aureus HP-S-01. Bioresour. Technol. 2012, 110, 97-104. [CrossRef] 
26. Akbar, S.; Sultan, S.; Kertesz, M. Determination of cypermethrin degradation potential of soil bacteria along with plant growth-promoting characteristics. Curr. Microbiol. 2015, 70, 75-84. [CrossRef]

27. Chen, S.; Dong, Y.H.; Chang, C.; Deng, Y.; Zhang, X.F.; Zhong, G.; Song, H.; Hu, M.; Zhang, L.H. Characterization of a novel cyfluthrin-degrading bacterial strain Brevibacterium aureum and its biochemical degradation pathway. Bioresour. Technol. 2013, 132, 16-23. [CrossRef]

28. Yang, J.; Feng, Y.; Zhan, H.; Liu, J.; Zhang, K.; Zhang, L.H.; Chen, S. Characterization of a pyrethroid-degrading Pseudomonas fulva strain P31 and biochemical degradation pathway of D-phenothrin. Front. Microbiol. 2018, 9, 1003. [CrossRef]

29. Li, J.; de Toledo, R.A.; Shim, H. Multivariate optimization for the simultaneous bioremoval of BTEX and chlorinated aliphatic hydrocarbons by Pseudomonas plecoglossicida. J. Hazard. Mater. 2017, 321, 238-246. [CrossRef]

30. Zhan, H.; Wang, H.; Liao, L.; Feng, Y.; Fan, X.; Zhang, L.H.; Chen, S. Kinetics and novel degradation pathway of permethrin in Acinetobacter baumannii ZH-14. Front. Microbiol. 2018, 9, 98. [CrossRef]

31. Chen, S.; Liu, C.; Peng, C.; Liu, H.; Hu, M.; Zhong, G. Biodegradation of chlorpyrifos and its hydrolysis product 3,5,6-trichloro-2-pyridinol by a new fungal strain Cladosporium cladosporioides Hu-01. PLoS ONE 2012, 7, e47205. [CrossRef]

32. Doraiswamy, N.; Sarathi, M.; Pennathur, G. Cross-linked esterase aggregates (CLEAs) using nanoparticles as immobilization matrix. Prep. Biochem. Biotechnol. 2019, 49, 270-278. [CrossRef]

33. Saez, J.M.; Aparicio, J.D.; Amoroso, M.J.; Benimeli, C.S. Effect of the acclimation of a Streptomyces consortium on lindane biodegradation by free and immobilized cells. Process Biochem. 2015, 50, 1923-1933. [CrossRef]

34. Naidu, Y.; Idris, A.S.; Nusaibah, S.A.; Norman, K.; Siddiqui, Y. In vitro screening of biocontrol and biodegradation potential of selected hymenomycetes against Ganoderma boninense and infected oil palm waste. Forest Pathol. 2015, 45, 474-483. [CrossRef]

35. Kaur, P.; Sharma, A.; Parihar, L. In vitro study of mycoremediation of cypermethrin-contaminated soils in different regions of Punjab. Ann. Microbiol. 2015, 65, 1949-1959. [CrossRef]

36. Wang, X.; Wang, X.; Liu, M.; Zhou, L.; Gu, Z.; Zhao, J. Bioremediation of marine oil pollution by Brevundimonas diminuta: Effect of salinity and nutrients. Desalin. Water Treat. 2016, 57, 19768-19775. [CrossRef]

37. Hechmi, N.; Bosso, L.; El-Bassi, L.; Scelza, R.; Testa, A.; Jedidi, N.; Rao, M.A. Depletion of pentachlorophenol in soil microcosms with Byssochlamys nivea and Scopulariopsis brumptii as detoxification agents. Chemosphere 2016, 165, 547-554. [CrossRef]

38. Maddela, N.R.; Burgos, R.; Kadiyala, V.; Carrion, A.R.; Bangeppagari, M. Removal of petroleum hydrocarbons from crude oil in solid and slurry phase by mixed soil microorganisms isolated from Ecuadorian oil fields. Int. Biodeter. Biodegr. 2016, 108, 85-90. [CrossRef]

39. Negi, G.; Pankaj; Sharma, A.; Srivastava, A. In situ biodegradation of endosulfan, imidacloprid, and carbendazim using indigenous bacterial cultures of agriculture fields of Uttarakhand, India. Int. J. Bioeng. Life Sci. 2014, 8, 973-981.

40. Ye, T.; Zhou, T.; Li, Q.; Xu, X.; Fan, X.; Zhang, L.; Chen, S. Cupriavidus sp. HN-2, a novel quorum quenching bacterial isolate, is a potent biocontrol agent against Xanthomonas campestris pv. campestris. Microorganisms 2020, 8, 45. [CrossRef]

41. Bhatt, P.; Gangola, S.; Chaudhary, P.; Khat, P.; Kumar, G.; Sharma, A.; Srivastava, A. Pesticide induced up-regulation of esterase and aldehyde dehydrogenase in indigenous Bacillus spp. Bioremediat J. 2019, 23, 42-52. [CrossRef]

42. Chen, S.; Deng, Y.; Chang, C.; Lee, J.; Cheng, Y.; Cui, Z.; Zhou, J.; He, F.; Hu, M.; Zhang, L.H. Pathway and kinetics of cyhalothrin biodegradation by Bacillus thuringiensis strain ZS-19. Sci. Rep. 2015, 5, 8784. [CrossRef]

43. Gangola, S.; Sharma, A.; Bhatt, P.; Khati, P.; Chaudhary, P. Presence of esterase and laccase in Bacillus subtilis facilitates biodegradation and detoxification of cypermethrin. Sci. Rep. 2018, 8, 12755. [CrossRef]

44. Tallur, P.N.; Mulla, S.I.; Megadi, V.B.; Talwar, M.P.; Ninnekar, H.Z. Biodegradation of cypermethrin by immobilized cells of Micrococcus sp. strain CPN 1. Brazilian J. Microbiol. 2015, 46, 667-672. [CrossRef]

45. Tang, A.X.; Liu, H.; Liu, Y.Y.; Li, Q.Y.; Qing, Y.M. Purification and characterization of a novel $\beta$-cypermethrin-degrading aminopeptidase from Pseudomonas aeruginosa GF31. J. Agric. Food Chem. 2017, 65, 9412-9418. [CrossRef]

46. Wang, B.; Guo, P.; Hang, B.; Li, L.; He, J.; Li, S.P. Cloning of a novel pyrethroid-hydrolyzing carboxylesterase gene from Sphingobium sp. strain JZ-1. Appl. Environ. Microbiol. 2009, 75, 5496-5500. [CrossRef] 
47. Bhatt, P.; Bhatt, K.; Huang, Y.; Lin, Z.; Chen, S. Esterase is a powerful tool for the biodegradation of pyrethroid insecticides. Chemosphere 2020, 244, 125507. [CrossRef]

48. Bhatt, P. Smart Bioremediation Technologies: Microbial Enzymes; Amesterdam Elsevier Science: London, UK, 2019. [CrossRef]

49. Armenta, S.; Quintás, G.; Garrigues, S.; De La Guardia, M. A validated and fast procedure for FTIR determination of cypermethrin and chlorpyrifos. Talanta 2005, 67, 634-639. [CrossRef]

50. Segal-Rosenheimer, M.; Dubowski, Y. Heterogeneous ozonolysis of cypermethrin using real-time monitoring FTIR techniques. J. Phys. Chem. C 2007, 111, 11682-11691. [CrossRef]

51. Fiorenza, R.; Mauro, A.D.; Cantarella, M.; Laria, C.; Scalisi, E.M.; Brundo, M.V.; Gulino, A.; Spitaleri, L.; Nicotra, G.; Datillo, S. Preferential removal of pesticides from water by molecular imprinting on $\mathrm{TiO}_{2}$ photocatalysts. Chem. Engi. J. 2020, 389, 122309. [CrossRef]

52. Chen, S.; Hu, W.; Xiao, Y.; Deng, Y.; Jia, J.; Hu, M. Degradation of 3-phenoxybenzoic acid by a Bacillus sp. PLOS ONE 2012, 7, e50456. [CrossRef]

53. Yang, L.; Chen, S.; Hu, M.; Liu, J. Biodegradation of carbofuran by Pichia anomala strain HQ-C-01 and its application for bioremediation of contaminated soils. Biol. Fert. Soils 2011, 47, 917-923. [CrossRef]

54. Zhao, H.M.; Hu, R.W.; Huang, H.B.; Wen, H.F.; Du, H.; Li, Y.W.; Li, H.; Cai, Q.Y.; Mo, C.H.; Liu, J.S.; et al. Enhanced dissipation of DEHP in soil and simultaneously reduced bioaccumulation of DEHP in vegetable using bioaugmentation with exogenous bacteria. Biol. Fertil. Soils 2017, 53, 663-675. [CrossRef]

55. Purkarthofer, T.; Skranc, W.; Schuster, C.; Griengl, H. Potential and capabilities of hydroxynitrile lyases as biocatalysts in the chemical industry. Appl. Microbiol. Biotechnol. 2007, 76, 309-320. [CrossRef]

56. Birolli, W.G.; Borges, E.M.; Nitschke, M.; Romão, L.P.C.; Porto, A.L.M. Biodegradation pathway of the pyrethroid pesticide esfenvalerate by bacteria from different biomes. Water Air Soil Poll. 2016, 227, 271. [CrossRef]

57. Birolli, W.G.; Arai, M.S.; Nitschke, M.; Porto, A.L.M. The pyrethroid ( \pm )-lambda-cyhalothrin enantioselective biodegradation by a bacterial consortium. Pest. Biochem. Physiol. 2019, 156, 129-137. [CrossRef]

58. Nakamura, T.; Ichinose, H.; Wariishi, H. Cloning and heterologous expression of two aryl-aldehyde dehydrogenases from the white-rot basidiomycete Phanerochaete chrysosporium. Biochem. Biophys. Res. Commun. 2010, 394, 470-475. [CrossRef]

59. Zhao, J.; Chi, Y.; Xu, Y.; Jia, D.; Yao, K. Co-metabolic degradation of $\beta$-cypermethrin and 3-phenoxybenzoic acid by co-culture of Bacillus licheniformis B-1 and Aspergillus oryzae M-4. PLoS ONE 2016, 11, e0166796. [CrossRef]

60. Zhai, Y.; Li, K.; Song, J.; Shi, Y.; Yan, Y. Molecular cloning, purification and biochemical characterization of a novel pyrethroid-hydrolyzing carboxylesterase gene from Ochrobactrum anthropi YZ-1. J. Hazard. Mater. 2012, 221-222, 206-212. [CrossRef]

61. Zhang, S.; Yin, L.; Liu, Y.; Zhang, D.; Luo, X.; Cheng, J.; Cheng, F.; Dai, J. Cometabolic biotransformation of fenpropathrin by Clostridium species strain ZP3. Biodegradation 2011, 22, 869-875. [CrossRef]

62. Fan, X.; Liu, X.; Huang, R.; Liu, Y. Identification and characterization of a novel thermostable pyrethroidhydrolyzing enzyme isolated through metagenomic approach. Microb. Cell Fact. 2012, 11, 33. [CrossRef]

63. Zhang, X.; Hao, X.; Huo, S.; Lin, W.; Xia, X.; Liu, K.; Duan, B. Isolation and identification of the Raoultella ornithinolytica-ZK4 degrading pyrethroid pesticides within soil sediment from an abandoned pesticide plant. Arch. Microbiol. 2019. [CrossRef]

64. Zhan, H.; Huang, Y.; Lin, Z.; Bhatt, P.; Chen, S. New insights into the microbial degradation and catalytic mechanism of synthetic pyrethroids. Environ. Res. 2020. [CrossRef]

65. Liu, J.; Chen, S.; Ding, J.; Xiao, Y.; Han, H.; Zhong, G. Sugarcane bagasse as support for immobilization of Bacillus pumilus HZ-2 and its use in bioremediation of mesotrione-contaminated soils. Appl. Microbiol. Biotechnol. 2015, 99, 10839-10851. [CrossRef]

(C) 2020 by the authors. Licensee MDPI, Basel, Switzerland. This article is an open access article distributed under the terms and conditions of the Creative Commons Attribution (CC BY) license (http://creativecommons.org/licenses/by/4.0/). 